Univerzitet u Beogradu

Fakultet za specijalnu edukaciju

i rehabilitaciju

\title{
RAZUMEVANJE IDIOMA KOD MLAĐIH I STARIJIH ODRASLIH OSOBA**
}

U jeziku postoje ustaljeni izrazi koji se sastoje od dve ili više reči. Oni imaju jedinstveno značenje koje se ne može izvesti na osnovu značenja pojedinačnih reči od kojih su sastavljeni. Takve jedinice u leksikonu su idiomi. S obzirom na frekventnost njihove upotrebe, razumevanje idioma je od velikog značaja za uspešnu komunikaciju.

Cilj rada je bio da se ispita sposobnost razumevanja idioma kod odraslih osoba budući da radovi stranih autora iz ove oblasti ne ukazuju nedvosmisleno da li ova sposobnost opada sa godinama. Uzorak je činilo 57 ispitanika podeljenih u dve uzrasne grupe (od 20 do 25 i od 70 do 90 godina) kod kojih se razumevanje idioma procenjivalo na osnovu definisanja deset izabranih izraza i navođenjem situacije u kojoj bi se dati primer mogao upotrebiti. Dobijeni rezultati nisu pokazali da ova sposobnost opada s godinama, ali je utvrđeno da ona i kod mlađih i kod starijih osoba zavisi od stepena izloženosti idiomima, kao i od stepena semantičke prozirnosti samog izraza. Rezultati su utoliko dragoceniji jer se odnose na ispitivanje kasnijeg jezičkog razvoja izvornih govornika srpskog jezika, te pored teorijskog mogu imati i praktični značaj kod usvajanja sintaksičkih i semantičkih svojstava leksema i izraza, kao i u radu sa decom kod koje su uočeni različiti oblici razvojnih jezičkih poremećaja.

Ključne reči: kasniji jezički razvoj, idiomi, semantika, sintaksa

\footnotetext{
*_majapivanovic@gmail.com

** Rad je realizovan u okviru projekata Jezici i kulture u vremenu i prostoru OI 178002 i Evaluacija tretmana stečenih poremé́aja govora i jezika OI 179068 koje finansira Ministarstvo prosvete, nauke i tehnološkog razvoja Republike Srbije.
} 


\section{UVOD}

U jeziku postoje lekseme koje su duže od jedne reči. Leksikon ih uglavnom određuje kao frazeologizme, frazeološke izraze (obrte), frazeme, ustaljene konstrukcije ili idiome. U zavisnosti od autora, svi navedeni termini mogu se manje-više upotrebljavati kao sinonimi, ili kao izrazi među kojima postoje izvesne razlike u značenju. U srbističkoj literaturi se spomenuti izrazi najčešće posmatraju kao ustaljene jezičke jedinice koje se sastoje od najmanje dve jedinice i imaju jedinstveno značenje, odnosno kod kojih se značenje celine ne može izvoditi iz značenja svake reči ponaosob iz koje se sastoji frazeologizam (Dragićević, 2007: 24).

Frazemi se tradicionalno tretiraju kao ustaljene sintagmatske ili predikativne celine čiji su leksički elementi uglavnom izgubili semantičku autonomnost i u toj jedinstvenoj vezi konotiraju nov sadržaj (Mršević Radović, 1987; Šipka, 2006; Šafer, 2016). Tako bi, u širem smislu, u frazeologizme mogle da se ubroje poslovice, izreke i aforizmi (Šipka, 2006).

Osim što značajno variraju od jezika do jezika, idiomi se i u okviru istog jezičkog sistema međusobno veoma razlikuju po sintaksičkim i semantičkim svojstvima, pa njihovo razumevanje može predstavljati problem čak i za izvorne govornike. Kako idiome razlikovati od običnih leksema u jeziku i koji nam mehanizmi signaliziraju da je uopšte reč o posebnim jedinicama leksikona, pitanja su koja tek poslednjih godina dobijaju neke od odgovora s obzirom da su se idiomi tradicionalno posmatrali kao dugačke, velike reči (giant words, Stock, Slack, et al., 1993), što samo po sebi ne zahteva posebnu analizu.

Sa semantičkog aspekta, idiomi predstavljaju skupove u kojima se svaka od leksema desemantizovala i izgubila svoju značenjsku autonomnost da bi u udruživanju sa ostalim leksemama učestvovala u formiranju nove, jedinstvene značenjske celine (Mršević Radović, 1987). Sa stanovišta sintakse, idiome odlikuje čvrsta struktura i uklapanje u kontekst (Matešić, 1982). U najvećem broju slučajeva idiomi predstavljaju prostu ili složenu leksičku jedinicu, čije bi se značenje moglo prevesti samo jednom rečju (na primer, otegnuti papke znači umreti; hvatati maglu - pobeći). S obzirom da idiomi predstavljaju specifične jedinice leksikona, oni imaju i neka posebna svojstva u odnosu na ostale lekseme. Međutim, idiomi se u značajnoj meri razlikuju i između sebe, pre svega u odnosu na stepen do kojeg mogu da istrpe morfološke i sintaksičke transformacije. Stepen 
do kojeg izraz može da toleriše pomeranja u sintaksičkom i morfološkom smislu zavisi od stepena okamenjenosti date konstrukcije. Prema stepenu prisustva ovog svojstva, idiomi mogu varirati od veoma okamenjenih do veoma fleksibilnih (Flores d'Arcais, 1993). U tom smislu, ne može se reći otegao je papak, nego samo otegao je papke; s druge strane, dozvoljeno je reći i poslednji modni krik i poslednji krik mode (Matešić, 1982). Drugo bitno obeležje idiomatskih konstrukcija je stepen semantičke prozirnosti. To je stepen udaljenosti figurativnog značenja od doslovnog, prema kome idiomi mogu imati u manjoj ili većoj meri predvidljivo značenje (Flores d' Arcais, 1993). Ovo svojstvo, u suštini, predstavlja odnos između doslovnog i prenesenog značenja idioma (Nippold \& Taylor, 1995). Na osnovu opisanih karakteristika pojedini idiomi se mogu definisati kao izrazi koji imaju samo metaforički upotrebljeno osnovno značenje, kao što je slučaj u primeru ići po tankom ledu ili roditi mečku, dok neki drugi, poput sisati vesla (nije neko sisao vesla), ili brati kožu na šiljak, imaju vrlo malo ili nimalo veze sa osnovnim značenjem (Gibbs, 1991). Izrazima koji su neprozirni nije moguće predvideti jedinstveno značenje na osnovu doslovnog značenja upotrebljenih leksema. Prema navedenim osobinama, idiomi mogu biti u većem ili manjem stepenu prozirni odnosno fleksibilni, pa se zbog toga ova variranja uglavnom svrstavaju u kategorije tipa više/manje, pre nego u one tipa da/ne. U pragmatskom smislu, značenje koje se pripisuje nekoj sintaksičkoj jedinici u skladu je sa kontekstom u okviru koga se jedinica ili konstrukcija javlja, što znači da jezičko okruženje može da obezbedi dodatnu informaciju o komunikativnim namerama govornika prilikom upotrebe datog izraza; drugim rečima, kontekst pruža informaciju na osnovu koje se može zaključiti i o značenju idioma. Ako su podaci iz konteksta ograničeni, sagovornik mora više da se osloni na svojstva samog idioma, a ukoliko je reč o manje prozirnom frazemu, kao što je sisati vesla (neko nije sisao vesla), brati kožu na šiljak, pažnja se mora posvetiti kontekstualnoj zavisnosti. Međutim, ako je izraz poznat i ako postoji prethodno iskustvo u vezi sa datom konstrukcijom, to svakako može da ublaži visok stepen netransparentnosti i izostanak kontekstualne podrške (Flores d' Arcais, 1993). Kod semantički prozirnijih izraza, do približnog značenja može da se dođe sabiranjem značenja pojedinačnih reči (ići po tankom ledu, roditi mečku, držati jezik za zubima).

S obzirom da značenje celine nije jednako zbiru značenja delova iz kojih se sastoji, jedna od nedoumica je i kako se ustaljeni izrazi skladište 
u mentalnom leksikonu. U vezi s tim, lingvističke teorije razmatraju tri modela: prvi polazi od pretpostavke da osim popisa leksičkih jedinica naš mentalni leksikon sadrži i spisak idioma. To znači da se za reči koje su deo idioma obavlja dvostruka pretraga - pretražuje se i lista običnih leksema i lista idioma. Prema drugom modelu, idiomi ne postoje kao posebne celine već se do značenja dolazi na osnovu značenja jedne ili više leksema koje su obeležene odgovarajućim oznakama za preneseno značenje. Treći pristup podrazumeva da značenje idioma nije uskladišteno kao takvo nego se otkriva svaki put na osnovu leksičke jedinice i sintagmatske strukture postupkom koji je sličan konstruisanju metafora (Flores d' Arcais, 1993).

Procesima koji su uključeni u razumevanje značenja idioma i ostalih frazeologizama najviše se bave istraživači kasnijeg jezičkog razvoja budući da se njihovi zameci javljaju u ranom detinjstvu i razvijaju tokom školskog uzrasta da bi se pouzdanija kompetencija za ovu leksičko-semantičku komponentu stekla tek u periodu adolescencije i u odraslom dobu (Ackerman, 1982; Brasseur \& Jimenez, 1989; Douglas \& Peel, 1979; Gibbs, 1987; Levorato \& Cacciari, 1992; Lodge \& Leach, 1975; Nippold \& Martin,1989; Nippold \& Rudzinski, 1993; Prinz, 1983; Strand \& Fraser, 1979; Thorum, 1986; prema Nippold \& Taylor, 1995). Ranije se mislilo da se obrada prenesenog značenja u jeziku odvija na drugačiji način. Smatralo se da sposobnost za produkciju i razumevanje idioma ne počiva na istim temeljima kao i opšta jezička sposobnost, pre svega zahvaljujući činjenici da je razumevanje figurativnog jezika osetljivije na kontekst od uobičajene upotrebe jezika. Značajan broj inostranih radova pokazuje da se idiomi lakše razumeju kad se jave u kontekstu nego kad su dati izolovano (Ackerman, 1982; Cacciari \& Levorato, 1989; Gibbs, 1987,1991; Levorato \& Cacciari, 1995; Nippold \& Martin, 1989; prema Nippold, Moran \& Schwarz, 2001), te da se kompetencija za razumevanje figurativnog značenja u maternjem jeziku razvija kada dete dostigne kognitivni nivo formalnih operacija (Smith, 1966, prema Nippold \& Taylor, 1995; Piaget, 2002).

Iako ne možemo sa sigurnošću reći kada se jezički razvoj pojedinca završava, znatan broj studija navodi da pojedini aspekti jezičke kompetencije opadaju posle sedamdesete godine života. Rezultati pojedinih studija su ukazali na progresiju teškoća u pristupu leksikonu kod starijih osoba (Barresi, 2000), kao i teškoća sa sintaksičkim procesiranjem koje se mogu javiti u poznijem dobu (Waters \& Caplan, 2001). S obzirom na 
to da se idiomi uče i skladište na sličan način kao i pojedinačne lekseme, tako se i njihovo prizivanje iz leksikona odvija na sličan način (Vulchanova, Saldaña, et al., 2015). Pored toga, obrada idioma se odvija na sličan način kao i sintaksičko procesiranje (Jackendoff \& Jackendoff, 2002; Vulchanova, Vulchanov, et al., 2011). Shodno navedenoj dualnoj prirodi idioma, moguće je da opadanje sposobnosti bilo leksičkog bilo sintaksičkog segmenta može uticati na sposobnost razumevanja idioma kod starijih osoba. Starije osobe sporije i nepreciznije imenuju i predmete i aktivnosti veoma frekventne u svakodnevnom životu, češće imaju teškoće u prisećanju poznatih reči tokom uobičajenih radnji (Burke \& Shafto, 2008, prema Hung \& Nippold, 2014). Slabljenje sposobnosti za prizivanje leksema iz mentalnog leksikona oko sedamdesete godine života pripisuje se oslabljenim vezama između uskladištenih leksičkih jedinica (i jednočlanih leksema i idioma) i njihovog glasovnog oblika. Pored toga, rezultati nekih studija ukazuju na povezanost kognitivnih sposobnosti (opseg radne memorije i egzekutivne sposobnosti) i razumevanja idioma (Fogliata et al., 2007; Papagno, Lucchelli, Muggia \& Rizzo, 2003; Qualls \& Harris, 2003, Schettino et al., 2010). Kako je, sa jedne strane, evociranje reči iz mentalnog leksikona sposobnost koja starenjem slabije funkcioniše, dok sa druge strane kognitivna fleksibilnost takođe opada sa godinama (Fisk \& Sharp, 2004), postavlja se pitanje da li sposobnost za razumevanje idioma ide uzlaznom linijom do kraja života ili i ona postepeno slabi posle sedamdesete godine.

Razumevanje idioma je opsežno istraživano u kliničkim populacijama (npr. Cacciari et al., 2006; Papagno et al., 2003; Qualls, et al., 2004; Vulchanova et al., 2015), kao i kod dece tipičnog razvoja (npr. Caillies \& Le Sourn Bissaoui, 2008; Cain, et al., 2009; Laval, 2003). Međutim, iako $\mathrm{u}$ literaturi postoji značajan broj studija koje su se bavile proučavanjem sposobnosti za razumevanje idioma kod starijih osoba i da li starenjem dolazi do slabljenja ove sposobnosti, istraživanja takvog tipa na srpskom govornom području još uvek nisu rađena. U jednoj od takvih studija na engleskom govornom području, istraživanju Kvalsove i Harisove (Qualls \& Harris, 2003), rezultati su pokazali da stariji ispitanici (54-73 god.) pokazuju bolje razumevanje idioma u poređenju sa mlađim odraslim ispitanicima (17-31 god.). Međutim, rezultati druge studije, sprovedene takođe među izvornim govornicima engleskog jezika u kojoj je uzorak ispitanika uključio znatno veći broj starijih govornika, ukazuju na propadanje spo- 
Maja P. Ivanović / Bojana J. Drljan

sobnosti za pripisivanje doslovnog značenja idiomima kod osoba starijih od 70 godina (Westbury \& Titone, 2011).

\section{CILJ RADA}

Osnovni cilj rada je bio da se ispita i bliže odredi sposobnost za razumevanje idioma kod odraslih osoba budući da studije stranih autora posvećene ovom pitanju ne ukazuju nedvosmisleno da li ova sposobnost opada s godinama. Takođe, s obzirom na to da specifičnosti različitih jezika mogu uticati na razumevanje idioma (Bortfeld, 2003), istraživanje na srpskom govornom području dobija na značaju. Idiomi se često mogu sresti u svakodnevnoj govornoj i pisanoj komunikaciji, uključujući i veliki broj televizijskih emisija, neformalne razgovore, predavanja, novinske članke, časopise, knjige i internet (Gibbs, Wilson, et al., 2012); s obzirom na frekventnost njihove upotrebe, nerazumevanje značenja idioma može dovesti do ozbiljne konfuzije između učesnika u komunikaciji. U užem smislu, cilj rada je bio da se ispita da li na razumevanje idioma utiče prethodno iskustvo, činjenica da su se govornici već ranije sreli sa tim izrazima, kao i to da li na razumevanje idioma utiče i stepen njihove semantičke prozirnosti. Rezultati bi mogli baciti više svetla na razvoj opšte jezičke sposobnosti i sam tok kasnijeg jezičkog razvoja pored toga što mogu poslužiti kao polazište za tumačenje teškoća koje neke osobe u zrelom dobu pokazuju prilikom leksičkog i semantičkog odlučivanja.

\section{METODOLOGIJA ISTRAŽIVANJA}

Ispitanici. Istraživanje je sprovedeno u junu i oktobru 2017. godine među studentima treće godine studijskog programa Logopedija Fakulteta za specijalnu edukaciju i rehabilitaciju Univerziteta u Beogradu i među korisnicima usluga Gerontološkog centra Beograd (Dom za stara lica Bežanijska kosa).

Nije bilo ispitanika sa neurološkim ili kognitivnim oštećenjima kao ni sa psihijatrijskim oboljenjima koja bi mogla da imaju uticaja na rezultate testa. Svi uključeni u istraživanje su izvorni govornici srpskog jezika; bilo ih je ukupno 57 a podeljeni su u dve uzrasne grupe - prvu grupu su činile mlade zdrave osobe od 20 do 25 godina, njih 29 (AS=21,9), dok je druga grupa sastavljena od 28 ispitanika uzrasta od 70 do 90 godina $(A S=79,6)$. Najstariji ispitanik je u trenutku sprovođenja istraživanja imao 
90 godina, a najmlađa ispitanica 20. Što se tiče polne strukture, u mlađoj grupi su bile sve osobe ženskog pola, a u starijoj je bilo 13 muškaraca i 15 žena. S obzirom da prvu grupu sačinjavaju studenti, svi su u procesu sticanja visokoškolskog obrazovanja, dok je u drugoj grupi bilo 8 muškaraca sa srednjom stručnom spremom, 3 sa višom i dva sa visokom, a među ženskim ispitanicima je bilo 4 sa završenom srednjom školom, 4 sa višom i 7 sa završenim fakultetom.

Opis instrumenta. Za potrebe istraživanja sastavljen je test za procenu razumevanja idioma. Test se sastojao od 10 idioma koji su dati izolovano, a od ispitanika se tražilo da zaokruže koliko puta su čuli svaki od ponuđenih primera koristeći petostepenu skalu Likertovog tipa: ovaj idiom sam čuo: (1) nikada do sada; (2) samo jednom; (3); retko; (4) više puta; (5) mnogo puta. U sledećem koraku se od ispitanika očekivalo da objasne značenje datog idioma, da ga definišu, dok se poslednji zahtev odnosio na opisivanje komunikativne situacije u kojoj bi se ponuđeni idiom mogao upotrebiti. Dobijeni odgovori su tumačeni i rangirani u skladu sa objašnjenjima koja se nalaze u Frazeološkom rječniku hrvatskoga ili srpskog jezika (Matešić, 1982). Idiomi od kojih je sastavljen test bili su: 1) loviti u mutnoj vodi - iskorištavati zamršenu, nesređenu priliku; nastojati šićariti, nečasno izvući korist iz nejasne, zamršene situacije (Matešić,1982: 748); 2) izvući deblji kraj - slabo proći u kakvom poslu; nadrljati, nastradati (Matešić, 1982: 272); 3) iznositi prljav veš - govoriti o nekome ružno; prljave stvari (Matešić, 1982: 593); 4) baciti nekome rukavicu - izazivati nekoga na dvoboj; stupiti u borbu; oštro se suprotstaviti u kakvu sporu (Matešić, 1982: 593); 5) biti na tri ćoška - biti neraspoložen, zle volje; ne biti u redu (Matešić, 1982: 75); 6) roditi mečku - s velikim naporom što uraditi, namučiti se dok se što uradi (Matešić, 1982: 334); 7) vaditi nekome mast - izmučiti nekoga, mrcvariti; dosađivati nekome; mučiti, naljutiti koga (Matešić, 1982: 116); 8) sedeti pa nemati kad - nemati što raditi, dosađivati se (Matešić, 1982: 764); 9) sisati vesla (nije neko sisao vesla) - ne biti lud, ne biti naivan (Matešić, 1982: 737); 10) brati kožu na šiljak - biti spreman na batine, na kaznu ili kakvu odgovornost (Matešić, 1982: 269).

Postupak sprovođenja istraživanja. Ispitanici prve grupe su rešavali opisani test za procenu razumevanja idioma u velikoj sali Fakulteta za specijalnu edukaciju i rehabilitaciju (jun 2017), a korisnici usluga doma za stara lica u zajedničkoj prostoriji Doma (oktobar 2017). Kako bi se ispitanici upoznali sa zadatkom, ispitivač je naglas pročitao uputstvo koje je 
Maja P. Ivanović / Bojana J. Drljan

dato u samom testu i na koje su ispitanici mogli i sami da se vraćaju više puta tokom rešavanja zadataka: Idiomi su izrazi koji imaju posebno značenje. Na primer, držati jezik za zubima je idiom koji znači ćutati. Može se upotrebiti u sledećoj situaciji: Marko polaže ispit, a Janko šapuće Marku dok odgovara. Ako profesor kaže:,Janko, drži jezik za zubima!", to znači da Janko treba da prestane da priča, da treba da ćuti. Upitnik koji je pred vama sastoji se od 10 idioma. Vi treba da zaokružite broj na skali koji se odnosi na to koliko su vam navedeni idiomi poznati. Pored toga, vaš zadatak je i da definišete svaki primer kao i da navedete konkretnu situaciju u kojoj bi idiom mogao da se upotrebi.

Kako se može videti, poznavanje i razumevanje idioma se procenjuje u odnosu na stepen prethodne izloženosti (koliko su ih puta ispitanici čuli) i u odnosu na to koliko nepostojanje konteksta doprinosi ili odmaže u razumevanju figurativnog značenja. Svaki od ponuđenih idioma sastoji se od jedne glagolske sintagme koja u svom sklopu ima od dve do četiri reči. Svi primeri su dati izolovano, bez konteksta koji bi mogao da nagovesti značenje.Vreme za odgovore je bilo neograničeno. Zadatak u kojem se traži da opišu situaciju u kojoj bi upotrebili dati idiom osmišljen je da se proveri razumevanje zbog toga što se samostalnim konstruisanjem konteksta potvrđuje znanje o leksičkoj semantici, što predstavlja dodatni kvalitet u leksičkom odlučivanju. Kriterijumi za bodovanje odgovora na svakom zadatku: 2 - odgovor je relevantan, jasan i potpun (tačan); 1- odgovor je relevantan, smislen, ali nejasan ili nepotpun (delimično tačan); 0 -odgovor je neodgovarajući ili ne postoji (netačan).

\section{REZULTATI SA DISKUSIJOM}

Dobijeni rezultati pružaju uvid u sposobnost za razumevanje idioma odraslih osoba koje su izvorni govornici srpskog jezika, ali i u to koliko postojeće iskustvo i frekventnost javljanja idioma utiče na definisanje njihovog značenja. Na osnovu dobijenih rezultata može se reći da sposobnost za razumevanje idioma mladih osoba i osoba iznad sedamdeset godina u velikoj meri korelira sa stepenom prethodne izloženosti idiomima i da je prethodno iskustvo u vezi sa njima relevantno za razumevanje njihovog značenja, što je u skladu sa zaključcima nekih inostranih studija (Nippold, 1985; Qualls \& Harris, 2003). 
RAZUMEVANJE IDIOMA KOD MLAĐIH I STARIJIH ODRASLIH OSOBA

Tabela 1

Deskriptivni pokazatelji rezultata ispitanika dve grupe na zadatku definisanja idioma na nivou pjedinačnih ajtema i ukupno

\begin{tabular}{|c|c|c|c|c|c|c|}
\hline \multirow[b]{2}{*}{ Idiom } & \multicolumn{3}{|c|}{$\begin{array}{c}\text { Korisnici usluga doma za stara } \\
\text { lica } N=28\end{array}$} & \multicolumn{3}{|c|}{$\begin{array}{l}\text { Studenti } \\
N=29\end{array}$} \\
\hline & $\begin{array}{l}\text { Min- } \\
\text { Max }\end{array}$ & $M$ & $S D$ & $\begin{array}{l}\text { Min- } \\
\text { Max }\end{array}$ & $M$ & $S D$ \\
\hline $\begin{array}{l}\text { loviti u } \\
\text { mutnoj } \\
\text { vodi }\end{array}$ & $0-2$ & 1,25 & 0,75 & $0-2$ & 0,38 & 0,73 \\
\hline $\begin{array}{l}\text { izvući } \\
\text { deblji } \\
\text { kraj }\end{array}$ & $0-2$ & 1,36 & 0,78 & $0-2$ & 1,72 & 0,65 \\
\hline $\begin{array}{l}\text { iznositi } \\
\text { prljav veš }\end{array}$ & $0-2$ & 1,43 & 0,74 & $0-2$ & 1,52 & 0,69 \\
\hline $\begin{array}{l}\text { baciti } \\
\text { nekome } \\
\text { rukavicu }\end{array}$ & $0-2$ & 1,32 & 0,91 & $0-2$ & 0,21 & 0,62 \\
\hline $\begin{array}{l}\text { biti na tri } \\
\text { ćoška }\end{array}$ & $0-2$ & 0,89 & 0,92 & $0-2$ & 0,45 & 0,83 \\
\hline $\begin{array}{l}\text { roditi } \\
\text { mečku }\end{array}$ & $0-2$ & 1,54 & 0,79 & $0-2$ & 1,34 & 0,81 \\
\hline $\begin{array}{l}\text { vaditi } \\
\text { nekome } \\
\text { mast }\end{array}$ & $0-2$ & 1,00 & 0,94 & $0-2$ & 1,00 & 1,00 \\
\hline $\begin{array}{l}\text { sedeti pa } \\
\text { nemati } \\
\text { kad }\end{array}$ & $0-2$ & 0,89 & 0,92 & $0-2$ & 0,48 & 0,83 \\
\hline $\begin{array}{l}\text { sisati } \\
\text { vesla }\end{array}$ & $0-2$ & 0,82 & 0,86 & $0-2$ & 1,90 & 0,41 \\
\hline $\begin{array}{l}\text { brati } \\
\text { kožu na } \\
\text { šiljak }\end{array}$ & $0-2$ & 0,64 & 0,87 & $0-2$ & 0,28 & 0,65 \\
\hline Ukupno & $3-20$ & 11,14 & 4,98 & $1-18$ & 9,28 & 3,29 \\
\hline
\end{tabular}


Ispitanicima je u obe grupe najmanje poznat izraz brati kožu na šiljak, najređe su se s njim sretali. S obzirom da mu je idiomatsko značenje neprozirno i prilično udaljeno od osnovnog, nisu ga mogli razumeti na odgovarajući način jer nije bilo ni podrške konteksta. Stariji ispitanici su takođe na netransparentnom izrazu sisati vesla (neko nije sisao vesla) imali najslabije postignuće, dok su studenti loš skor imali i na definisanju idioma baciti nekome rukavicu. Slabo postignuće u primeru 8 - sedeti pa nemati kad, naročito kod mladih, može se tumačiti kao posledica toga što je njegovo značenje suprotno osnovnom, pa je moglo da utiče na ispitanike da se odluče da ga posmatraju kao izrazito proziran frazem, isključujuću figurativnu komponentu. I jedni i drugi su najbolje objasnili idiome roditi mečku, iznositi prljav veš i izvući deblji kraj. Osim ovih, studenti su imali uspeha u definisanju izraza loviti u mutnoj vodi, dok su stariji u najvećem broju uspešno definisali primer na kojem su studenti pokazali najslabije razumevanje, reč je o idiomu sisati vesla.

Kod frazeologizama čije se značenje teže može prozreti iz doslovnog dolazi do nerazumevanja jer su teži za dešifrovanje. Time se potvrđuje stav da se različite strategije primenjuju na različite vrste idioma - neki se uče holistički, a kod nekih se značenje izvlači iz osnovnog značenja reči od kojih su formirani (Nippold \& Taylor, 1995). U suštini, prema jednoj od dve glavne strategije usvajanja idioma značenju se pristupa direktno i u celini. Tu je u velikoj meri prisutno oslanjanje na učestalost pojavljivanja izraza i stepen izloženosti govornika takvim izrazima. Prema drugoj se do prenesenog značenja stiže preko osnovnog i ona prednjači kad je reč o prozirnijim idiomima (Flores d' Arcais, 1993).

Međugrupne razlike u definisanju idioma ispitane su primenom multivarijantne analize varijanse (MANOVA), sa grupom kao faktorom (nezavisnom varijablom) i učinkom na pojedinačnim zadacima kao zavisnim varijablama. Rezultati MANOVA-e pokazuju da postoji značajan efekat grupe na tačnost definisanja idioma (Wilks' $\lambda=.29, F(10,46)=$ $11,93, p<, 001)$, čime se potvrđuje da su stariji ispitanici i statistički značajno uspešniji od studenata u definisanju zadatih idioma. Kako pokazuju rezultati naknadne jednofaktorske analize varijanse, ova ukupna razlika je značajno determinisana razlikama u postignuću ispitanika dve grupe na sledećim idiomima: loviti u mutnoj vodi $(F(1)=19,75, p<, 001)$, baciti nekome rukavicu $(F(1)=29,61, p<, 001)$ i sisati vesla $(F(1)=36,52, p<$ 
,001). U slučaju sva tri idioma, postignuće starijih ispitanika je statistički značajno bolje.

Rezultati našeg istraživanja potvrđuju rezultate dobijene u studiji Kvalsove i Harisove (Qualls \& Harris, 2003). Međutim, prosečna starost starijih ispitanika u našem i u navedenom istraživanju se razlikuju $(79,6$ vs. 63,25), tako da naši rezultati pokazuju da sposobnost razumevanja idioma ne opada ni posle sedamdesete godine. Sa druge strane, rezultati istraživanja studije Vestburija i Titonove (Westbury \& Titone, 2011), koje je obuhvatilo i strarije ispitanike $(A S=70,3)$, ukazali su na usporavanje procesa pripisivanja doslovnog značenja idiomatskim strukturama kao i na to da su stariji osetljiviji na raskorak između doslovnog i figurativnog značenja (Westbury \& Titone, 2011). Kao posredan dokaz koji ide u prilog rezultatima do kojih su došli autori u prethodno navedenoj studiji a odnose se na slabljenje sposobnosti za pripisivanje neidiomatskog značenja idiomatskim konstrukcijama u poznim godinama, mogu se smatrati odgovori jednog broja naših ispitanika u starijoj grupi koji su, gde im se činilo prikladnim, jedan idiom objašnjavali drugim, na primer: mutne radnje (loviti u mutnoj vodi); dobiti po ušima (izvući deblji kraj); ...iznositi ružne stvari o neistomišljenicima...pa ni Dunav ni Sava ne mogu da vas operu (iznositi prljav veš); nisu mi sve koze na broju; neraspoložen, pa još ako imate kratak fitilj, onda može da bude krvi do kolena; nakrivo nasađena; sedeti na iglama (biti na tri ćoška); izvući deblji kraj (roditi mečku); isterivati ,,mak na konac" (vaditi nekome mast); odbiti da te neko nasanka na tanak led (nije neko sisao vesla) i dr. Ovo je značajno zbog toga što se na ovaj način favorizuje model obrade idioma koji podrazumeva njihovu semantičku celovitost i obaveznost pripisivanja prenesenog značenja ovakvim jedinicama leksikona (npr. Libben \& Titone, 2008; Titone \& Connine, 1999; prema Westbury \& Titone, 2011).

U Tabeli II su izneseni rezultati koji se odnose na iskustvo koje ispitanici obeju grupa imaju u upotrebi datih idioma. 
Maja P. Ivanović / Bojana J. Drljan

Tabela 2

Deskriptivni pokazatelji iskustva ispitanika obe grupe u upotrebi pojedinačnih idioma i ukupno

\begin{tabular}{|c|c|c|c|c|c|c|}
\hline \multirow[b]{2}{*}{ Idiom } & \multicolumn{3}{|c|}{$\begin{array}{c}\text { Korisnici usluga doma za stara } \\
\text { lica } N=28\end{array}$} & \multicolumn{3}{|c|}{$\begin{array}{l}\text { Studenti } \\
N=29\end{array}$} \\
\hline & $\begin{array}{l}\text { Min- } \\
\text { Max }\end{array}$ & $M$ & $S D$ & $\begin{array}{l}\text { Min- } \\
\text { Max }\end{array}$ & $M$ & $S D$ \\
\hline $\begin{array}{l}\text { loviti u } \\
\text { mutnoj } \\
\text { vodi }\end{array}$ & $0-2$ & 1,25 & 0,75 & $0-2$ & 0,38 & 0,73 \\
\hline $\begin{array}{l}\text { izvući } \\
\text { deblji } \\
\text { kraj }\end{array}$ & $0-2$ & 1,36 & 0,78 & $0-2$ & 1,72 & 0,65 \\
\hline $\begin{array}{l}\text { iznositi } \\
\text { prljav veš }\end{array}$ & $0-2$ & 1,43 & 0,74 & $0-2$ & 1,52 & 0,69 \\
\hline $\begin{array}{l}\text { baciti } \\
\text { nekome } \\
\text { rukavicu }\end{array}$ & $0-2$ & 1,32 & 0,91 & $0-2$ & 0,21 & 0,62 \\
\hline $\begin{array}{l}\text { biti na tri } \\
\text { ćoška }\end{array}$ & $0-2$ & 0,89 & 0,92 & $0-2$ & 0,45 & 0,83 \\
\hline $\begin{array}{l}\text { roditi } \\
\text { mečku }\end{array}$ & $0-2$ & 1,54 & 0,79 & $0-2$ & 1,34 & 0,81 \\
\hline $\begin{array}{l}\text { vaditi } \\
\text { nekome } \\
\text { mast }\end{array}$ & $0-2$ & 1,00 & 0,94 & $0-2$ & 1,00 & 1,00 \\
\hline $\begin{array}{l}\text { sedeti pa } \\
\text { nemati } \\
\text { kad }\end{array}$ & $0-2$ & 0,89 & 0,92 & $0-2$ & 0,48 & 0,83 \\
\hline $\begin{array}{l}\text { sisati } \\
\text { vesla }\end{array}$ & $0-2$ & 0,82 & 0,86 & $0-2$ & 1,90 & 0,41 \\
\hline $\begin{array}{l}\text { brati } \\
\text { kožu na } \\
\text { šiljak }\end{array}$ & $0-2$ & 0,64 & 0,87 & $0-2$ & 0,28 & 0,65 \\
\hline Ukupno & $3-20$ & 11,14 & 4,98 & $1-18$ & 9,28 & 3,29 \\
\hline
\end{tabular}


Najfrekventniji idiomi sa kojima su se sretali i korisnici doma za stara lica i studenti su - izvući deblji kraj, iznositi prljav veš, za starije još i roditi mečku, biti na tri ćoška i loviti u mutnoj vodi, za mlađe govornike veoma poznat je i izraz sisati vesla. Spomenuti idiomi imaju visok nivo prethodnog iskustva, odgovori se prosečno kreću od 4,79 do 4,50 za izvući deblji kraj, odnosno od 4,61 do 4,14 za iznositi prljav veš. U grupi u kojoj su stariji govornici postoje pojedinci koji nikada nisu čuli idiome brati kožu na šiljak, sedeti pa nemati kad i vaditi nekome mast, dok su u grupi studenata svi ispitanici makar jednom čuli svaki od ponuđenih primera. Najređe su se u obe grupe sretale sa idiomima brati kožu na šiljak $(2,46$, odnosno 1,59) i sedeti pa nemati kad $(2,64$ odnosno 1,31) dok su pored ovih, stariji najmanje puta čuli još i sisati vesla, a studenti baciti nekome rukavicu i vaditi nekome mast.

Rezultati su pokazali da na razumevanje idioma kod mladih odraslih osoba od 20 do 25 godina, kao i kod osoba između 70 i 90 godina veoma utiče izloženost takvim konstrukcijama; razumevanje, zapravo, u velikoj meri korelira sa prethodnim iskustvom i činjenicom da se idiomi koji su se čuli više ili mnogo puta, lakše prepoznaju i razumeju od idioma koji su nepoznati. S druge strane, idiomi čije je metaforičko značenje bliže doslovnom značenju reči od kojih su sastavljeni, u semantičkom smislu su transparentniji, lakše se razumeju jer jača veza između dva značenja može biti od pomoći prilikom dekodiranja idioma koji su potpuno nepoznati. Rezultati izneti u ovom radu, dobijeni analizom materijala prikupljenog među izvornim govornicima srpskog jezika, potvrđuju rezultate prethodnih istraživanja na drugim govornim područjima (npr. Chan \& Marinellie, 2008; Nippold \& Rudzinski, 1993; Nippold \& Taylor, 1995; Hung \& Nippold, 2014). S druge strane, inostrani radovi takođe navode da je razumevanje bolje ako su idiomi prezentovani u kontekstu; ako ispitanik ima kontekstualnu podršku koja podupire njegovu figurativnu interpretaciju nego ako su idiomi dati samostalno (npr. Gibbs, 1987; Levorato \& Cacciari, 1999; Nippold \& Martin, 1989; Hung \& Nippold, 2014). Međutim, ovde se pokazalo da će, ukoliko su idiomi odranije poznati, značenje koje im se pripisuje u najvećem broju slučajeva biti odgovarajuće i da razumevanje izraza u celini neće izostati usled nedostatka konteksta. Inostrane studije takođe navode da je razumevanje idioma osetljivo na stepen metaforične transparentnosti (npr. Gibbs, 1987; Nippold \& Duthie, 2003; Nippold \& Rudzinski, 1993; Nippold \& Taylor, 1995; Hung \& Nippold, 2014), što su potvrdili i razultati koji su ovde izneseni. U većini primera do razumevanja se došlo zahvaljujući pre svega frekventnoj upotrebi, pa je ispitanicima 
bilo lakše da ih razumeju i navedu situaciju u kojoj bi mogli da ih upotrebe jer ona već postoji u njihovom komunikativnom iskustvu. Prema hipotezi jezičkog iskustva, razvoj figurativnog jezika u velikoj meri zavisi od stepena izloženosti konstrukcijama koje nemaju doslovno značenje (Ortony, Turner, et al., 1985). To znači da se idiomima koji imaju frekventniju upotrebu lakše pripisuju metaforična značenja i da su lakši za razumevanje.

Međugrupne razlike $u$ iskustvu sa zadatim idiomima ispitane su primenom multivarijantne analize varijanse (MANOVA), sa grupom kao faktorom (nezavisnom varijablom) $\mathrm{i}$ iskustvom u pojedinačnim zadacima kao zavisnim varijablama. Rezultati MANOVA-e pokazuju da postoji značajan efekat grupe na iskustvo u upotrebi idioma $\left(\right.$ Wilks' $^{\prime} \lambda=.26, F(10,46)=$ $13,01, p<, 001)$, čime se potvrđuje da su stariji ispitanici bili u većoj meri izloženi zadatim idiomima nego studenti. Kako pokazuju rezultati naknadne jednofaktorske analize varijanse, ova ukupna razlika je posledica statistički značajne razlike u iskustvu sa gotovo svim idiomima, izuzev idioma izvući deblji kraj i iznositi prljav veš gde se ne dobijaju statistički značajne razlike u odnosu na prethodni nivo iskustva. O statistički značajno većem iskustvu starijih ispitanika u upotrebi idioma govore primeri: loviti u mutnoj vodi $(F(1)=30,99, p<, 001)$, baciti nekome rukavicu $(F(1)=73,74$, $p<, 001)$, biti na tri ćoška $(F(1)=12,96, p<, 01)$, roditi mečku $(F(1)=$ $5,65, p<, 05)$, vaditi nekome mast $(F(1)=10,48, p<, 01)$, sedeti pa nemati kad $(F(1)=19,70, p<, 001)$ i brati kožu na šiljak $(F(1)=5,59, p<, 05)$. Jedino u slučaju idioma sedeti pa nemati kad mlađi ispitanici izveštavaju o većoj izloženosti ustaljenim konstrukcijama $(F(1)=6,60, p<, 05)$.

$\mathrm{Na}$ kraju je unutar svake od grupa ispitana povezanost uspešnosti u definisanju idioma sa prethodnim iskustvom u okviru zadatih idioma. Rezultati korelacione analize pokazuju da je uspeh u definisanju idioma statistički značajno pozitivno povezan sa prethodnim iskustvom koje ispitanici imaju u upotrebi idioma koji su im ponuđeni. U grupi korisnika usluga doma za stare korelacija je visoka $(r=, 70, p<, 001)$, a u grupi studenata umerene visine $(r=, 51, p<, 001)$.

$\mathrm{Na}$ osnovu iznetih rezultata može se zaključiti da su adekvatne odgovore prilikom definisanja značenja idioma ispitanici dali upravo za one izraze koje su čuli više puta, koji su im poznati i koji imaju najviši stepen semantičke prozirnosti. Generalno bi se moglo reći da stariji ispitanici najbolje razumeju idiome koji su im već poznati zato što su ih najviše puta čuli i one koji im nisu poznati ali čije su značenje mogli da naslute na osnovu male razlike između dva tipa značenja. 


\section{Zaključak}

Rezultati koji su izloženi u ovom radu ne ukazuju da dolazi do opadanja sposobnosti razumevanja idioma kod starih osoba. Skorašnja ispitivanja potvrđuju da za razumevanje idioma nema jedinstvene strategije, već da način na koji se ovakvi izrazi definišu zavisi od same strukture izraza. Dok se jedni usvajaju holostički, za druge važi razuđenija strategija kod kojih se preneseno značenje nazire iz osnovnog značenja reči iz kojih se sastoji (Gibbs, 1987; 1991; Nippold \& Rudzinski, 1993). Faktori koji utiču na razumevanje idioma su frekventnost upotrebe i stepen prozirnosti značenja. Osim toga, kontekst je bitan činilac razumevanja frazeologizama, ali kada su primeri dati samostalno, razumevanje neće trpeti ukoliko su izrazi poznati od ranije - što su se ispitanici više puta sreli s njima, bolje su ih razumeli i objasnili. S druge strane, ukoliko se sa nekim idiomom sreću prvi put, razumevanje će biti olakšano kod primera koji se mogu okarakterisati kao prozirniji tj. kao oni čije je preneseno značenje bliže osnovnom. Idiomi koji postoje u komunikativnom iskustvu i koji spadaju u prozirnije, lakši su za razumevanje od onih koji su nepoznati i čije je značenje netransparentno.

\section{LITERATURA.}

Barresi, B. A., Nicholas, M., Tabor Connor, L., Obler, L. K., \& Albert, M. L. (2000). Semantic degradation and lexical access in age-related naming failures. Aging, Neuropsychology, and Cognition, 7(3), 169-178.

Bortfeld, H. (2003). Comprehending idioms cross-linguistically. Experimental psychology, 50(3), 217-230.

Cacciari, C., Reati, F., Colombo, M. R., Padovani, R., Rizzo, S., \& Papagno, C. (2006). The comprehension of ambiguous idioms in aphasic patients. $\mathrm{Ne}$ uropsychologia, 44(8), 1305-1314.

Caillies, S., \& Le Sourn-Bissaoui, S. (2008). Children's understanding of idioms and theory of mind development. Developmental Science, 11(5), 703-711.

Cain, K., Towse, A. S., \& Knight, R. S. (2009). The development of idiom comprehension: An investigation of semantic and contextual processing skills. Journal of experimental child psychology, 102(3), 280-298.

Chan, Y-L., \& Marinellie, S. A. (2008). Definitions of idioms in preadolescents, adolescents, and adults. Journal of Psycholinguistic Research, 37, 1-20.

Dragićević, R. (2007). Leksikologija srpskog jezika. Beograd: Zavod za udžbenike.

Fisk, J. E., \& Sharp, C. A. (2004). Age-related impairment in executive functi- 
Maja P. Ivanović / Bojana J. Drljan

oning: Updating, inhibition, shifting, and access. Journal of clinical and experimental neuropsychology, 26(7), 874-890.

Flores d' Arcais, G. (1993). The Comprehension and Semantic Interpretation of Idioms. In C. Cacciari, P. Tabossi (eds), IDIOMS: Processing, Structure, and Interpretation (pp. 79-99). Hillsdale, New Jersey Hove and London: Lawrence Erlbaum Associates.

Fogliata, A., Rizzo, S., Reati, F., Miniussi, C., Oliveri, M., \& Papagno, C. (2007). The time course of idiom processing. Neuropsychologia, 45(14), 32153222.

Gibbs, R. W. (1987). Linguistic factors in children's understanding of idioms. Journal of Child Language, 14, 569-586.

Gibbs, R. W. (1991). Semantic analyzability in children's understanding of idioms. Journal of Speech and Hearing Research, 34, 613-620.

Gibbs, R. W., Wilson, N. L., \& Bryant, G. A. (2012). Figurative language: Normal adult cognitive research. In M. J. Spivey, K. McRae, \& M. F. Joanisse (eds), The Cambridge handbook of psycholinguistics (pp. 465-484) New York: Cambridge University Press.

Hung, P. F., Nippold, M. A. (2014). Idiom understanding in adulthood: examining age-related differences. Clinical Linguistics \& Phonetics, 28(3), 208-221.

Jackendoff, R., \& Jackendoff, R. S. (2002). Foundations of language: Brain, meaning, grammar, evolution. USA: Oxford University Press.

Laval, V. (2003). Idiom comprehension and metapragmatic knowledge in French children. Journal of Pragmatics, 35(5), 723-739.

Levorato, M. C. (1993). The Acquisition of Idioms and the Development of Figurative Competence. In C. Cacciari, P. Tabossi (eds), IDIOMS: Processing, Structure, and Interpretation (pp. 101-129). Hillsdale, New Jersey Hove and LOndon: Lawrence Erlbaum Associates.

Matešić, J. (1982). Frazeološki rječnik hrvatskoga ili srpskog jezika. Zagreb: Školska knjiga.

Mršević Radović, D. (1987). Frazeološke glagolsko-imeničke sintagme u savremenom srpsko- hrvatskom jeziku. Beograd: Filološki fakultet.

Nippold, M. A. (1985). Comprehension of figurative language in youth. Topics in language disorders, 5, 1-20.

Nippold, M. A., \& Duthie, J. K. (2003). Mental imagery and idiom comprehension: A comparison of school-age children and adults. Journal of Speech, Language, and Hearing Research, 46, 788-799.

Nippold, M. A., \& Rudzinski, M. (1993). Familiarity and transparency in idiom explanation: A developmental study of children and adolescents. Journal of Speech and Hearing Research, 36, 728-737. 
Nippold, M. A., Moran, C., Schwarz I. E. (2001). Undestanding in Preadolescents: Synergy in Action. American Journal of speech-language patho$\log y, 10(2), 169-179$.

Nippold, M. A., Tarrant Martin, S. (1989). Idiom interpretation in isolation versus context: A developmental study with adolescents. Journal of Speech and Hearing Research, 32, 59-66.

Nippold, M. A., Taylor, C. L. (1995). Idiom Understanding in Youth: Further Examination of Familiarity and Transparency. Journal of Speech and Hearing Research, 38, 426-433.

Ortony, A., Turner, T. J., \& Larson-Shapiro, N. (1985). Cultural and instructional influences on figurative language comprehension by inner city children. Research in the Teaching of English, 19, 25-36.

Papagno, C., Lucchelli, F., Muggia, S., \& Rizzo, S. (2003). Idiom comprehension in Alzheimer's disease: The role of the central executive. Brain, 126(11), 2419-2430.

Piaget, J. (2002). The language and thought of the child. Psychology Press.

Qualls, C. D., \& Harris, J. L. (2003). Age, Working Memory, Figurative Language Type, and Reading Ability. American Journal of Speech-Language Pathology, 12, 92-102.

Qualls, C. D., Lantz, J. M., Pietrzyk, R. M., Blood, G. W., \& Hammer, C. S. (2004). Comprehension of idioms in adolescents with language-based learning disabilities compared to their typically developing peers. Journal of Communication Disorders, 37(4), 295-311.

Šafer, M. (2016). Frazeologizmi sa leksemama đavo (vrag)/devil u srpskom i engleskom jeziku. Zbornik za jezike i književnosti Filozofskog fakulteta u Novom Sadu. Novi Sad: Filozofski fakultet, 159-191.

Šipka, D. (2006). Osnovi leksikologije i srodnih disciplina. Novi Sad: Matica srpska.

Schettino, A., Lauro, L. R., Crippa, F., Anselmetti, S., Cavallaro, R., \& Papagno, C. (2010). The comprehension of idiomatic expressions in schizophrenic patients. Neuropsychologia, 48(4), 1032-1040.

Stock, O., Slack, J., Ortony, A. (1993). Building Castles in the Air. Some computational and Theoretical Issues in Idiom Comprehension'. In C. Cacciari, P. Tabossi (eds), IDIOMS: Processing, Structure, and Interpretation. (229-249). Hillsdale, New Jersey Hove and London: Lawrence Erlbaum Associates.

Vulchanova, M., Vulchanov, V., \& Stankova, M. (2011). Idiom comprehension in the first language: a developmental study. Vigo International Journal of Applied Linguistics, 8(1), 207-234. 
Vulchanova, M., Saldaña, D., Chahboun, S., \& Vulchanov, V. (2015). Figurative language processing in atypical populations: the ASD perspective. Frontiers in human neuroscience, 9, 24.

Waters, G. S., \& Caplan, D. (2001). Age, working memory, and on-line syntactic processing in sentence comprehension. Psychology and aging, 16(1), $128-144$.

Westbury, C., \& Titone, D. (2011). Idiom literality judgments in younger and older adults: Age-related effects in resolving semantic interference. Psychology and aging, 26(2), 467-474.

Maja P. Ivanović

Bojana J. Drljan

THE ABILITY TO UNDERSTAND IDIOMS IN YOUNGER AND OLDER ADULTS

Summary

There are well-established terms in a language that consist of two or more words. They have a unique meaning that cannot be derived from the meaning of individual words of which they are composed. Units with this status in the lexicon are idioms. Given the frequency of their use, understanding idioms is of great importance for successful communication.

The aim of the paper was to examine the ability to understand idioms in adults, since the work of foreign authors about issue does not clearly indicate whether this ability declines with ageing. A total of 57 subjects were divided into two age groups ( 20 to 25 and 70 to 90 years of age) in which the understanding of the idiom was assessed by defining ten selected terms and describing the situation in which the example could be used. The results obtained did not show that this ability declines with age, but it was found that in both younger and older adults it depends on the degree of exposure to idioms as well as on the degree of semantic transparency of the expression itself. The results are even more valuable as they relate to the examination of the later language development in native speakers of Serbian, and in addition to theoretical, they may have practical value in the acquisition of syntactic and semantic features of lexemes and expressions, as well as, in the work with children who have manifested different forms of developmental linguistic disorders.

Key words: later language development, idioms, semantics, syntax 